\title{
Clinoptilolite-rich mineral as a novel carrier for the active constituents present in Ginkgo biloba leaf extract
}

\author{
Selda Göktaş ${ }^{1}$, Semra Ülkü, Oguz Bayraktar* \\ Biochemical Engineering Research Laboratory (BERL), Department of Chemical Engineering, \\ Izmir Institute of Technology, Gülbahçe Köyü, 35430, Urla-Izmir, Turkey
}

Received 30 May 2007; received in revised form 6 June 2007; accepted 16 June 2007

Available online 5 July 2007

\begin{abstract}
The possible use of clinoptilolite-rich mineral as a novel carrier for the active constituents present in Ginkgo biloba leaf extract solutions was investigated. The flavonoid aglycone constituents were found to be selectively adsorbed on the clinoptilolite surface. The antioxidant activity determinations of the extract solutions were performed by the Trolox Equivalent Antioxidant Capacity (TEAC) assay. The antioxidant activity measurements performed for the Ginkgo leaf extract solutions showed decreasing antioxidant activities due to adsorption. The decrease in antioxidant activity was attributed to the adsorption of phenolic constituents on the clinoptilolite surface.
\end{abstract}

(C) 2007 Elsevier B.V. All rights reserved.

Keywords: Ginkgo biloba; Flavonoids; Antioxidant; Clinoptilolite; Adsorption

\section{Introduction}

Nowadays, herbal remedies are becoming more popular than ever before as far as the possible adverse effects of synthetic drugs are concerned. Among those herbal medicines, Ginkgo biloba extract is one of the most popular phytopharmaceuticals with its unique properties which make it superior to its competitors. Its therapeutic activities were determined by numerous pharmacological and clinical studies as the enhancement of blood circulation while decreasing the viscosity of blood, promotion of mental clarity (Ponto and Schultz,

\footnotetext{
* Corresponding author. Tel.: +90 232750 6657; fax: +90 232750 6645 .

E-mail address: oguzbayraktar@iyte.edu.tr (O. Bayraktar).

${ }^{1}$ Current address: School of Chemical, Biological and Materials Engineering, University of Oklahoma, Norman, Oklahoma 73019, USA.
}

2003), acting as a powerful antioxidant (Li and Fitzloff, 2002), PAF (platelet aggregation factor) antagonism (Chiu et al., 2002; Yoon et al., 1997), slowing down the progression of cognitive deficits such as Alzheimer's disease (Lang and Wai, 1999; Li and Fitzloff, 2002), treatment of vertigo and tinnitus (Dubber et al., 2005). Ginkgolides, a group of unique diterpene lactones and flavonoids have been proved to be pharmacologically active constituents of Ginkgo biloba L. extracts ( $\mathrm{Li}$ and Fitzloff, 2002; Ndjoko et al., 2000; Xu et al., 2000). All commercially available Ginkgo biloba products are standardized for their flavonol glycoside content $(24 \%$ $\mathrm{w} / \mathrm{w})$ and terpene lactone content $(6 \% \mathrm{w} / \mathrm{w})(\mathrm{Xu}$ et al., 2000; Xu et al., 2005; van Beek, 2002).

Many studies have reported that flavonol glycosides exhibit biological activities, including antiallergenic, antivirial, anti-inflammatory, and vasodilating actions (Wang et al., 2003). The most compromising action of 
flavonoids is that they act as potent natural antioxidants by scavenging reactive oxygen species (ROS), including the superoxide radical $\left(\mathrm{O}_{2}^{-1} \bullet\right)$, hydroxyl radicals $(\mathrm{HO} \bullet)$, peroxyl radicals $(\mathrm{ROO} \bullet)$ and nitric oxide $(\mathrm{NO} \bullet)$ while terminating their chain reactions (Goh et al., 2003; Pietta et al., 2000; Wood et al., 2002). Also if one considers the fact that flavonoids can chelate some metal ions such as $\mathrm{Cu}^{2+}$ and $\mathrm{Fe}^{2+}$, the effectiveness of these constituents as natural antioxidants can be better understood (EllnainWojtaszek et al., 2002, 2003).

However, the quantification of the total amount of flavonol glycosides present in Ginkgo biloba leaf extracts is a difficult task due to lack of commercially available pure standards and their great variety. Fortunately, flavonol glycosides can be converted to their three major aglycone derivatives-isorhamnetin, kaempferol and quercetin, via acidic hydrolysis which enables the quantification of total flavonoids by RPHPLC in terms of these commercially available aglycone structures (van Beek, 2002; Yu et al., 2003).

Although the organic solvents provide the extraction of the metabolites from plants, further purification can be essential in order to obtain concentrated specific components selectively because many other compounds such as sugars, protein, or metals may exist in the plant extracts (Yoon et al., 1997; Aehle et al., 2004). For the selective recovery of target plant metabolites from the crude solvent extracts, adsorption is preferred by many of the researchers, because it is a low-cost separation technique (Aehle et al., 2004; Baycin et al., 2007).

There exist a few studies regarding the adsorption of Ginkgo biloba leaf extract constituents in literature. Yu et al. (2003) investigated the adsorption of flavonoid glycosides on the surface of adsorptive membranes including commercial hydrophobic and anion-exchange membranes. Xu et al. (2000) synthesized macroporous polymethacrylate beads via suspension polymerization of methacrylate (MA) and divinylbenzene (DVB) as crosslinker. Thus, they obtained a kind of adsorbent with high selectivity for ginkgo flavonol glycosides and terpene lactones. In another study, Xu et al. (2005) synthesized spherical adsorbents derived from the glutaraldehyde cross-linked hybrid of gelatin and polyvinyl alcohol (PVA) and investigated their adsorption selectivity for ginkgo flavonol glycosides and terpene lactones in detail. They found that an adsorbent with appropriate gelatin content could selectively adsorb flavonol glycosides with a high adsorption capacity based mainly on hydrogen bonding interactions, while showing only a fairly low adsorption capacity for terpene lactones. Besides, Yoon et al. (1997) developed a simple purification method in which flavonoid compounds were selectively adsorbed onto a polycarboxyl ester resin (XAD-7) from methanol extract of ginkgo leaves.

Because of their promising health effects, three major aglycone derivatives-isorhamnetin, kaempferol and quercetin, can be removed from hydrolyzed Ginkgo biloba leaf extract by adsorption techniques. If a medicinal adsorbent such as clinoptilolite-rich mineral can be used in the adsorption of isorhamnetin, kaempferol and quercetin, then there will be no need for a desorption step, and in this way clinoptilolite-rich mineral will gain antioxidative, antimicrobial, and antiinflammatory properties for further use in pharmaceutical applications.

Zeolites are natural or synthetic mesoporous or microporous silicate and alumosilicate crystals. They can be used as catalysts, ionexchangers, adsorbents, nonspecific immunostimulators and adjuvants in anticancer therapy (Poljak-Blazi et al., 2001). Natural zeolite (NZ) and their modified forms have been evaluated as a gastric antacid, anti-diarrheic, anti-hyperglicemyc, hipocholosterolemic and as a matrix for the release of ions and organic molecules. These products are considered as active principles, therefore, it is important from the pharmaceutical point of view, to determine if the coadministration with conventional drugs is possible (Farias et al., 2003; Rivera and Farias, 2005).

The use of the natural zeolites in animal health and nutrition, and also their long-term chemical and biological stability has been studied in the literature. Pavelic et al. (2001) reported that clinoptilolite treatment of mice and dogs suffering from a variety of tumor types led to improvement in the overall health status, prolongation of life-span, and decrease in tumor size. Clinoptilolite tends to neutralize the aqueous medium acting either as proton acceptor or as a proton donor due to its amphoteric character. For example, if an appropriate dosage of clinoptilolite is able to increase the stomach $\mathrm{pH}$, and to decrease the intestine $\mathrm{pH}$ as it goes through the gastrointestinal tract, it may modify the absorption of certain drugs at both organs (Rivera et al., 2000). Rivera et al., (2003) studied the adsorption of the model drugs-metronidazole, sulfamethoxazole and aspirin-on the purified natural clinoptilolite from Tasajeras deposit in Cuba to investigate the possibility of using this mineral as carrier in slow-release dosage forms. Zinc exchanged clinoptilolite-rich rock was used as active carrier for antibiotics in anti-acne topical therapy (Cerri et al., 2004; Bonferoni et al., 2007). Again silver exchanged clinoptilolite was found to be promising anti bacterial material (Top and Ülkü, 2004). Mixture of clinoptilolite with pulverised dried leaves of Utrica 
dioica was studied as a potential antioxidant (Sverko et al., 2004).

Considering the purported therapeutic efficacies of Ginkgo biloba leaf extract and the possible use of clinoptilolite as a drug support, the clinoptilolite-rich mineral was experimented to be used as a novel drug carrier for the active constituents in Ginkgo biloba L. extract (GBE) solutions.

\section{Materials and methods}

\subsection{Materials}

Quercetin, Kaempferol, Isorhamnetin and Trolox were purchased from Fluka. Internal standard, Morin was obtained from Sigma. Ethanol, hydrochloric acid (37\%) and trifluoroacetic acid (TFA) were from Merck Co. (Hohenbrunn, Germany). All solvents were HPLC grade. ABTS $\left[2,2^{\prime}-\right.$ azinobis-(3-ethylbenzothiazoline-6-sulfonic acid)] was purchased from Sigma (Steinheim, Germany). Clinoptilolite-rich mineral was collected from Gördes (Manisa, Turkey) deposit in the western part of Turkey (Enli Madencilik A.Ş.).

The fresh Ginkgo leaves were collected from a male Ginkgo tree in Izmir (Turkey) at the end of August 2004. August was chosen for the collection time for the leaf material, since the concentration of therapeutically active constituents are claimed to be at their lowest level during Spring and increase until late Summer or early Autumn (Chiu et al., 2002).

\subsection{Extract preparation}

Collected leaves were washed with deionized water prior to drying stage. Then, the leaves were oven dried for three consecutive days at $37^{\circ} \mathrm{C}$. The dried leaves were pulverized in a blender at full speed while pausing for 1-2 min to prevent the frictional heating of the leaf powder (Mantle et al., 2000). Then, the thoroughly-mixed leaf powder (having particle sizes of $75-150 \mu \mathrm{m}$ and $300-500 \mu \mathrm{m}$ ) was stored in tightened light protected glass bottles till further use.

Ethanol/water solution was used for extraction of the active constituents present in leaf material. Ethanol was preferred as extracting solvent due to its nontoxic nature for dietary purposes. The solid:liquid ratio was selected as 1:10 for all experiments. The $\mathrm{pH}$ of the solutions were adjusted by adding appropriate amounts of $3 \mathrm{M}$ aqueous $\mathrm{HCl}$. Extraction was achieved in a temperature-controlled shaking water bath. Extracted solutions were centrifuged at a constant speed of $3,000 \mathrm{rpm}$ for $10 \mathrm{~min}$. Supernatants were further filtered through $0.45 \mu \mathrm{m}$ syringe filter.

\subsection{Preparation of the zeolitic material}

The clinoptilolite-rich mineral was crushed in jaw crusher (FLISCHER). The crushed samples were further wet-sieved into different particle size ranges $(25-75 \mu \mathrm{m}, 75-150 \mu \mathrm{m}$,
$150-300 \mu \mathrm{m}, 300-425 \mu \mathrm{m}$ and $425-850 \mu \mathrm{m}$ ) with deionized water several times in order to remove water-soluble impurities. Wet-sieving was continued until no more suspended material was observed in the remaining solution. The wet-sieved clinoptilolite-rich mineral was put into oven at $200{ }^{\circ} \mathrm{C}$ for $24 \mathrm{~h}$. The dried clinoptilolite-rich mineral was placed over saturated $\mathrm{NH}_{4} \mathrm{Cl}$ solution in order to equilibrate with water vapor prior to adsorption experiments.

\subsection{Adsorption of the ethanolic leaf extract}

Batch adsorption studies were conducted using a constant temperature water bath $\left(30^{\circ} \mathrm{C}\right)$ by shaking the flasks at $180 \mathrm{rpm}$. Twenty $\mathrm{ml}$ of the ethanolic leaf extracts were subjected to adsorption with $0.5,2,5$ and $10 \mathrm{~g}$ zeolitic material for $24 \mathrm{~h}$. The resultant solutions were filtered over $0.45 \mu \mathrm{m}$ syringe filter and kept at $+4{ }^{\circ} \mathrm{C}$ until further analysis.

\subsection{Chromatographic conditions}

For the separation and detection of the active constituents within the ethanolic extract of Ginkgo biloba L., LiChrospher RP-18 column having dimensions of $3 \times 250 \mathrm{~mm}$ and a packing particle size of $5 \mu \mathrm{m}$ was used. The column temperature was set at $30^{\circ} \mathrm{C}$. A step gradient elution system was adopted with the mobile phases; A: water containing $5 \%$ methanol and $0.05 \%$ Trifluoroacetic acid (TFA) and B: methanol containing $0.05 \% \mathrm{TFA}$, with the following profile: 0-35 min, $75-25 \%$ A, $25-75 \%$ B; 35-36 min, 25-10\% A, $75-90 \% \mathrm{~B} ; 36-42 \mathrm{~min}$, isocratic $10 \% \mathrm{~A}, 90 \% \mathrm{~B} ; 42-43 \mathrm{~min}$, $10-75 \% \mathrm{~A}, 90-25 \% \mathrm{~B} ; 43-50 \mathrm{~min}$, isocratic $75 \% \mathrm{~A}, 25 \% \mathrm{~B}$ (Li and Fitzloff, 2002). The flow rate was $1 \mathrm{ml} \mathrm{min}^{-1}$.

\subsubsection{Quantification of flavonol glycosides}

Acidic hydrolysis was accomplished by treating $20 \mathrm{ml}$ of filtered supernatant with $20 \mathrm{ml} 5.5 \% \mathrm{HCl}$ solution for $30 \mathrm{~min}$ in a shaking water bath at $85^{\circ} \mathrm{C}$ with $200 \mathrm{rpm}$. After cooling, the solutions were filtered through $0.45 \mu \mathrm{m}$ syringe filter prior to HPLC analysis.<smiles>O=c1c(O)c(-c2ccc(O)c(Br)c2)oc2cc(O)cc(O)c12</smiles>

$$
\begin{array}{ll}
\text { Quercetin } & \mathrm{R}_{1}=\mathrm{OH} \\
\text { Kaempferol } & \mathrm{R}_{1}=\mathrm{H} \\
\text { Isorhamnetin } & \mathrm{R}_{1}=\mathrm{OCH}_{3}
\end{array}
$$

Fig. 1. Chemical structure of the three aglycones in hydrolyzed extracts of Ginkgo biloba L. 
To prepare calibration curves of quercetin, kaempferol, isorhamnetin (Fig. 1), each aglycone standard was accurately weighed (approximately $5 \mathrm{mg}$ each) and dissolved separately in $80 \%$ methanol solution to give final concentrations of 500 , 110,55 , and $25 \mu \mathrm{g} \mathrm{ml}^{-1}$ for quercetin, 450, 100, 50, and $25 \mu \mathrm{g}$ $\mathrm{ml}^{-1}$ for kaempferol and 250, 55, 25, and $15 \mu \mathrm{g} \mathrm{ml}^{-1}$ for isorhamnetin. Internal standard method was used where morin (internal standard) with a final concentration of $440 \mu \mathrm{g} / \mathrm{ml}$ was spiked into each dilution ( Lin et al., 2000). Then, the standards were filtered through a $0.45-\mu \mathrm{m}$ syringe filter before injecting to the column. The flavonoid compounds, quercetin, kaempferol and isorhamnetin and the internal standard, morin, yielded retention times as 17.0, 22.4, 21.3 and $14.5 \mathrm{~min}$, respectively, at a detection wavelength of $350 \mathrm{~nm}$. The calibration curves were obtained by performing a linear regression analysis of the peak area ratios of the aglycones to the internal standard versus the aglycone concentrations.

The total flavonol glycoside content was evaluated from the peak areas of quercetin, kaempferol and isorhamnetin using the following formula (Yu et al., 2003; Lai et al., 2003; Gray et al., 2006).

$\Sigma$ (concentration of each aglycone) $2.51=$ total concentration of flavonol glycosides where the concentration of each aglycone was determined from the calibration curves for the aglycone standards, and 2.51 is the averaged conversion factor for the three aglycones with reference to the molecular weight of flavonol coumaroyl ester glycosides (MW=756.7).

\subsection{Measurement of total antioxidant activity}

According to "ABTS Radical Cation Decolorization Assay" as described by Re et al. (1999), ABTS (2,2'-azinobis-(3-ethylbenzothiazoline-6-sulfonic acid)) was dissolved in water to a $7 \mathrm{mM}$ concentration. ABTS radical cation $\left(\mathrm{ABTS}^{+}\right.$) was produced by reacting ABTS stock solution with $2.45 \mathrm{mM}$ potassium persulfate (final concentration) and allowing the mixture to stand in the dark at room temperature for $12-16 \mathrm{~h}$ before use. Because ABTS and potassium persulfate react stoichiometrically at a ratio of 1:0.5, this will result in incomplete oxidation of the ABTS. The radical was stable in this form for more than two days when stored in the dark room at room temperature.

The $\mathrm{ABTS}^{+}$solution was diluted with ethanol to an absorbance of $0.7( \pm 0.02)$ at $734 \mathrm{~nm}$ and equilibrated at $30^{\circ} \mathrm{C}$. Stock solutions of phenolics in ethanol were diluted such that, after introduction of a $10 \mu \mathrm{l}$ aliquot of each dilution into the assay, they produced between $20-80 \%$ inhibition of the blank absorbance. After addition of $1.0 \mathrm{ml}$ of diluted ABTS ${ }^{+}$ solution $\left(A_{734 \mathrm{~nm}}=0.700 \pm 0.02\right)$ to $10 \mu \mathrm{l}$ of antioxidant compounds or Trolox standards (final concentration 0$15 \mu \mathrm{M})$ in ethanol, the absorbance reading was taken at $30{ }^{\circ} \mathrm{C}$ exactly $1 \mathrm{~min}$ after initial mixing and up to $6 \mathrm{~min}$. The percentage inhibition of absorbance at $734 \mathrm{~nm}$ was calculated and plotted as a function of concentration of antioxidants and of Trolox for the standard reference data.

\section{Results and discussion}

\subsection{Adsorption studies}

Adsorption studies were performed at four different solid-to-liquid ratios by adjusting the amount of zeolite $(0.5,2,5$ and $10 \mathrm{~g}$ clinoptilolite-rich mineral). Fig. 2 shows the scanning electron microscope (SEM) micrographs of clinoptilolite samples used in the experimental study after washing and drying step prior to adsorption process. The concentration of aglycones and total flavonoid glycosides in Ginkgo biloba extract solution
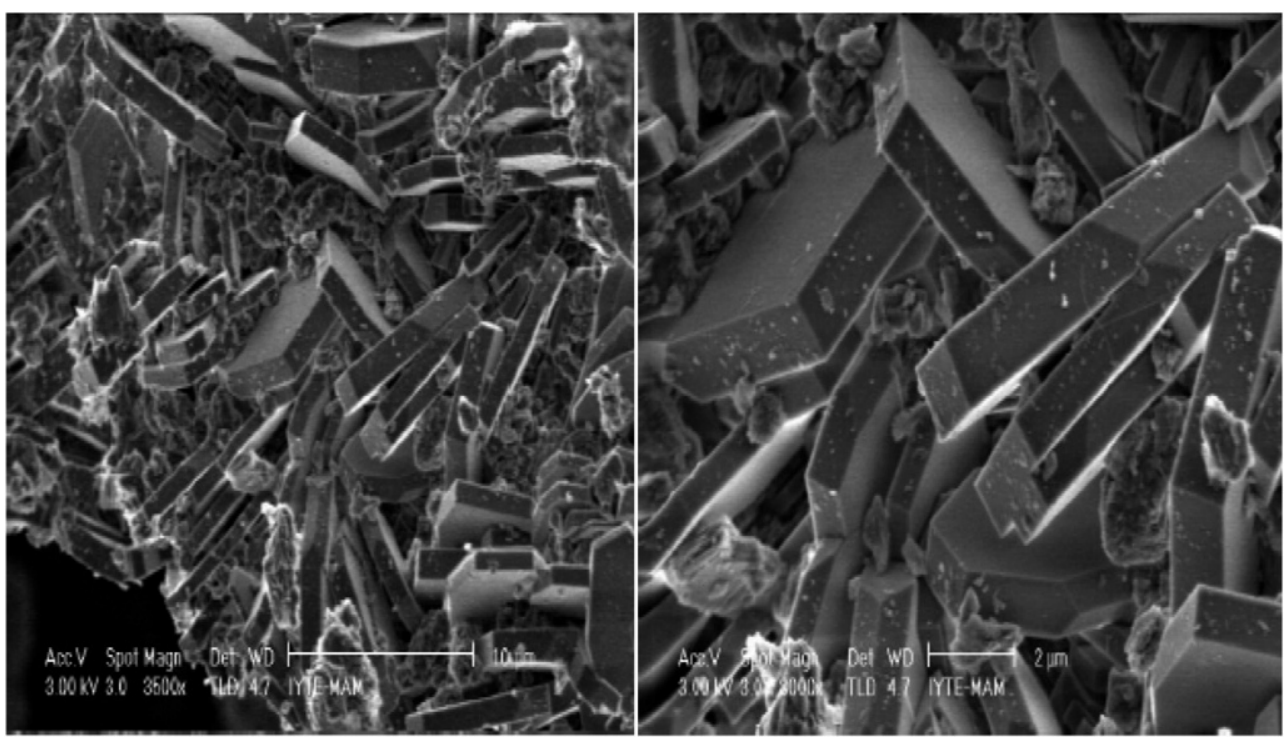

Fig. 2. SEM micrographs of clinoptilolite samples used in the experimental study after washing and drying step prior to adsorption process. 
Table 1

Adsorption results for the three aglycone constituents and the total flavonoid content for different solid loadings

\begin{tabular}{lllll}
\hline & \multicolumn{2}{l}{ Concentration $\left(\mu \mathrm{g} \mathrm{ml}^{-1}\right)$} & \\
\cline { 2 - 5 } & Quercetin $^{\mathrm{a}}$ & Kaempferol $^{\mathrm{a}}$ & Isorhamnetin $^{\mathrm{a}}$ & Total flavonoid glycosides $^{\mathrm{b}}$ \\
\hline Before adsorption & 45.54 & 62.28 & 21.29 & 324.07 \\
After adsorption with 0.5 g zeolite & 42.93 & 61.02 & 21.28 & 314.33 \\
After adsorption with 2 g zeolite & 31.06 & 45.38 & 17.63 & 236.11 \\
After adsorption with 5 g zeolite & 20.02 & 32.07 & 11.09 & 158.56 \\
After adsorption with 10 g zeolite & 7.41 & 15.98 & 4.65 & 70.39 \\
\hline
\end{tabular}

${ }^{\text {a }}$ Mean values obtained from triplicate injections.

b $\Sigma$ (amount of each aglycone) $\times 2.51=$ total amount of flavonoid glycosides.

before and after adsorption are given in Table 1. When $0.5 \mathrm{~g}$ of clinoptilolite-rich mineral was used there was no significant amount of aglycone constituents adsorbed on clinoptilolite-rich mineral. With increasing clinoptilolite-rich mineral loading to the adsorption medium, the adsorbed quantities increased sharply as tabulated in Table 1. Since the cyclo-or benzene structures in the molecular configuration of flavonoid glycosides are hydrophobic, and the-OH residuals in the phenolic groups possibly form anions ( Yu et al., 2003), it would be certainly very difficult to adsorb flavonol glycosides based on the usually mentioned surface physical adsorption mechanism. Therefore, the adsorption mechanism of flavonoid aglycones could rather be explained by hydrogen-bonding interactions with the zeolitic material, since flavonoid aglycones are effective hydrogen bonding donors ( Xu et al., 2000).

In order to investigate the effect of initial solution concentration on adsorption of flavonoid aglycone constituents, three different concentrations $(75,100$ and $125 \mathrm{~g}$ dry leaf material per liter of $80 \%$ ethanol solution) were experimented. The zeolite amount added to each extract solution was constant as $10 \mathrm{~g}$. The percent adsorbed amounts increased with increasing initial solution concentration as presented in Table 2 . For $75 \mathrm{~g}^{-1}$ initial solution concentration, the percent decrease in the amount of quercetin, kaempferol and isorhamnetin were calculated as 29.96, 16.10 and $31.17 \%$, respectively. For $100 \mathrm{~g}^{-1}$ initial solution concentration, the percent decrease in the amount of quercetin, kaempferol and isorhamnetin were 37.43, 29.63 and $42.41 \%$, respectively. For $125 \mathrm{~g} \mathrm{l}^{-1}$ initial solution concentration, these values were evaluated as $58.61,31.92$ and $46.69 \%$, respectively. Finally, the percent decrease in the amount of total flavonoid glycosides for 75,100 , and $125 \mathrm{~g} \mathrm{l}^{-1}$ were calculated as $23.50,34.31$ and 42.96 , respectively.

Fig. 3 shows the changes in the amounts of adsorbed flavonoids with varying clinoptilolite-rich mineral amounts. Adsorbed amounts of quercetin, kaempferol and isorhamnetin increased significantly with increasing clinoptilolite-rich mineral. Since the molecular size of the extracted species were much greater than the dimensional size of the clinoptilolite channels, only surface adsorption phenomena was expected to occur. Adsorption studies showed that flavonoid aglycone constituents were adsorbed on the surface of the zeolitic material. The time profile of adsorbed quercetin, kaempferol, isorhamnetin on $5 \mathrm{~g}$ clinoptilolite-rich mineral was given in Fig. 4. As seen from this figure, Adsorption reached almost in equilibrium within $4 \mathrm{~h}$. Adsorbed amounts of quercetin, kaempferol and isorhamnetin per gram of clinoptilolite-rich mineral were found to be $14,8,23 \mu \mathrm{g}$.

Table 2

Amounts of each aglycone constituent before and after adsorption with $10 \mathrm{~g}$ clinoptilolite-rich mineral due to varying initial solution concentrations

\begin{tabular}{|c|c|c|c|c|}
\hline Initial solution concentration $\left(\mathrm{g} \mathrm{l}^{-1}\right)$ & & $75 \mathrm{~g} \mathrm{l}^{-1}$ & $100 \mathrm{~g}^{-1}$ & $125 \mathrm{~g}^{-1}$ \\
\hline \multirow[t]{2}{*}{ Quercetin concentration $^{\mathrm{a}}\left(\mu \mathrm{g} \mathrm{ml}^{-1}\right)$} & Before adsorption & 107.15 & 126.53 & 148.76 \\
\hline & After adsorption & 75.05 & 79.17 & 61.57 \\
\hline \multirow{2}{*}{ Kaempferol concentration $^{\mathrm{a}}\left(\mu \mathrm{g} \mathrm{ml}^{-1}\right)$} & Before adsorption & 180.54 & 218.59 & 249.66 \\
\hline & After adsorption & 151.48 & 153.82 & 169.98 \\
\hline \multirow[t]{2}{*}{ Isorhamnetin concentration $^{\mathrm{a}}\left(\mu \mathrm{g} \mathrm{ml}^{-1}\right)$} & Before adsorption & 83.81 & 77.64 & 115.42 \\
\hline & After adsorption & 57.69 & 44.72 & 61.53 \\
\hline \multirow[t]{2}{*}{ Total amount of flavonoid glycosides $\left(\mu \mathrm{g} \mathrm{ml}^{-1}\right)$} & Before adsorption & 932.48 & 1061.13 & 1289.71 \\
\hline & After adsorption & 713.37 & 697.03 & 735.62 \\
\hline
\end{tabular}

Mean values obtained from triplicate injections.

${ }^{\mathrm{a}} \Sigma$ (amount of each aglycone) $2.51=$ total amount of flavonoid glycosides. 


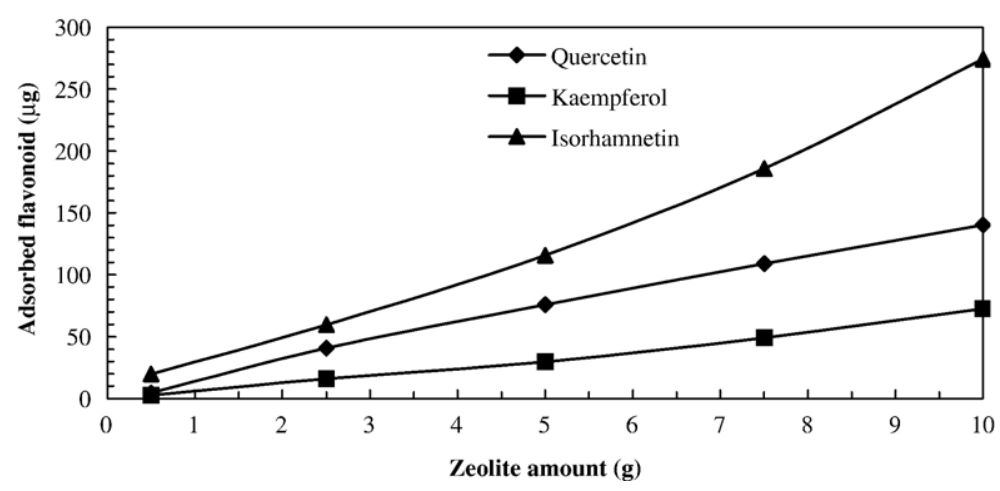

Fig. 3. Effect of clinoptilolite-rich mineral amount on the adsorption of flavonoids.

\subsection{Antioxidant activity determinations}

The antioxidant activity measurements of the extract solutions were performed according to the TEAC (Trolox Equivalent Antioxidant Capacity) assay reported by Re et al. (1999). The inhibition of the ABTS free radical by different extract solutions as a function of time were evaluated. The more rapidly the absorbance decreases, the more potent the antioxidant activity of the extract solution. Since the absorbance decreased more sharply for the leaf extract solution when compared with the extract solutions after adsorption with clinoptilolite-rich mineral, the antioxidant activity of initial extract solution was the greatest. This clearly showed that antioxidant compounds in extract solution were adsorbed on the surface of clinoptilolite-rich mineral. The smaller decrease in the absorbance values due to adsorption demonstrated the decrease in the total antioxidant activity of the extract solution due to adsorbed flavonoid aglycones on clinoptilolite-rich mineral.

In order to examine the effect of the adsorbent amount on the antioxidant activity of the extract solutions, Fig. 5A-C were compared for $0.025 \mathrm{~g} \mathrm{ml}^{-1}$ and $0.05 \mathrm{~g} \mathrm{ml}^{-1}$ solution concentrations, since $0.01 \mathrm{~g} \mathrm{ml}^{-1}$, $0.013 \mathrm{~g} \mathrm{ml}^{-1}$ and $0.017 \mathrm{~g} \mathrm{ml}^{-1}$ solution concentrations did not yield comparable decrease in absorbance vs. time plots. Regarding that the initial absorbance values were the same, the absorbance values recorded at the end of 6 min for $0.025 \mathrm{~g} \mathrm{ml}^{-1}$ solutions as $A_{t=6} \min =0.394$ and $A_{t=6 \mathrm{~min}}=0.483$ for 5 and $10 \mathrm{~g}$ clinoptilolite-rich mineral additions, respectively. Also for $0.05 \mathrm{~g} \mathrm{ml}^{-1}$ solutions, these values were recorded as $A_{t=6} \min =0.394$ and $A_{t=6 \mathrm{~min}}=0.483$ for 5 and $10 \mathrm{~g}$ linoptilolite-rich mineral

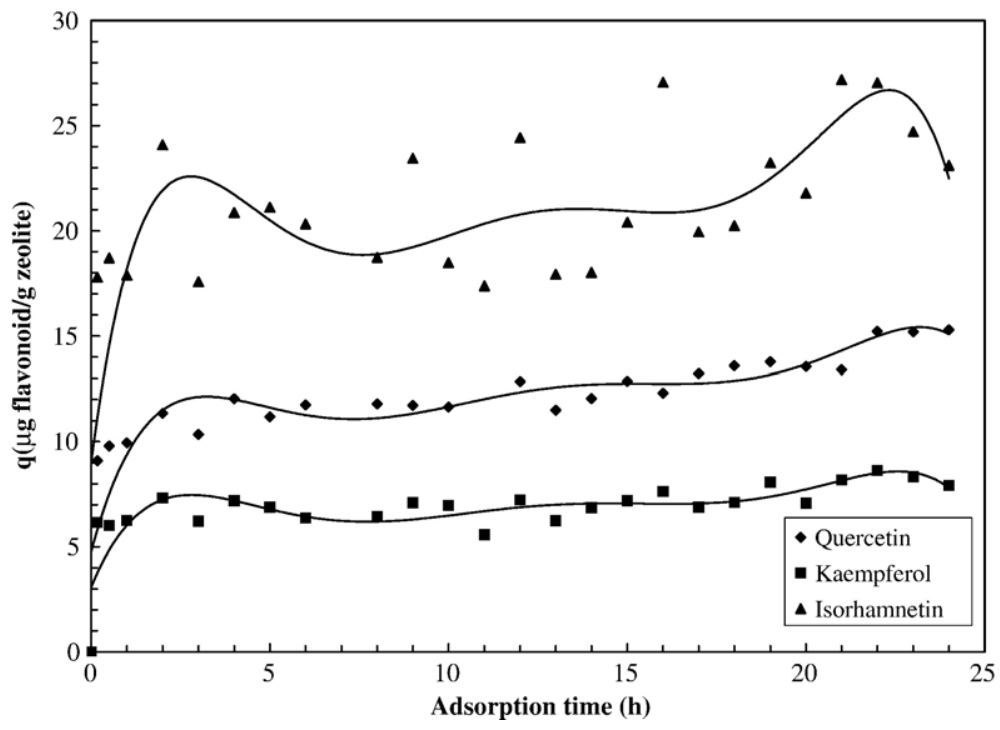

Fig. 4. The time profile of adsorbed quercetin, kaempferol, isorhamnetin onto $5 \mathrm{~g}$ clinoptilolite-rich mineral with an initial flavonoid amount of $190 \mu \mathrm{g}, 160 \mu \mathrm{g}, 470 \mu \mathrm{g}$ in $20 \mathrm{ml}$ extract solution, respectively. 

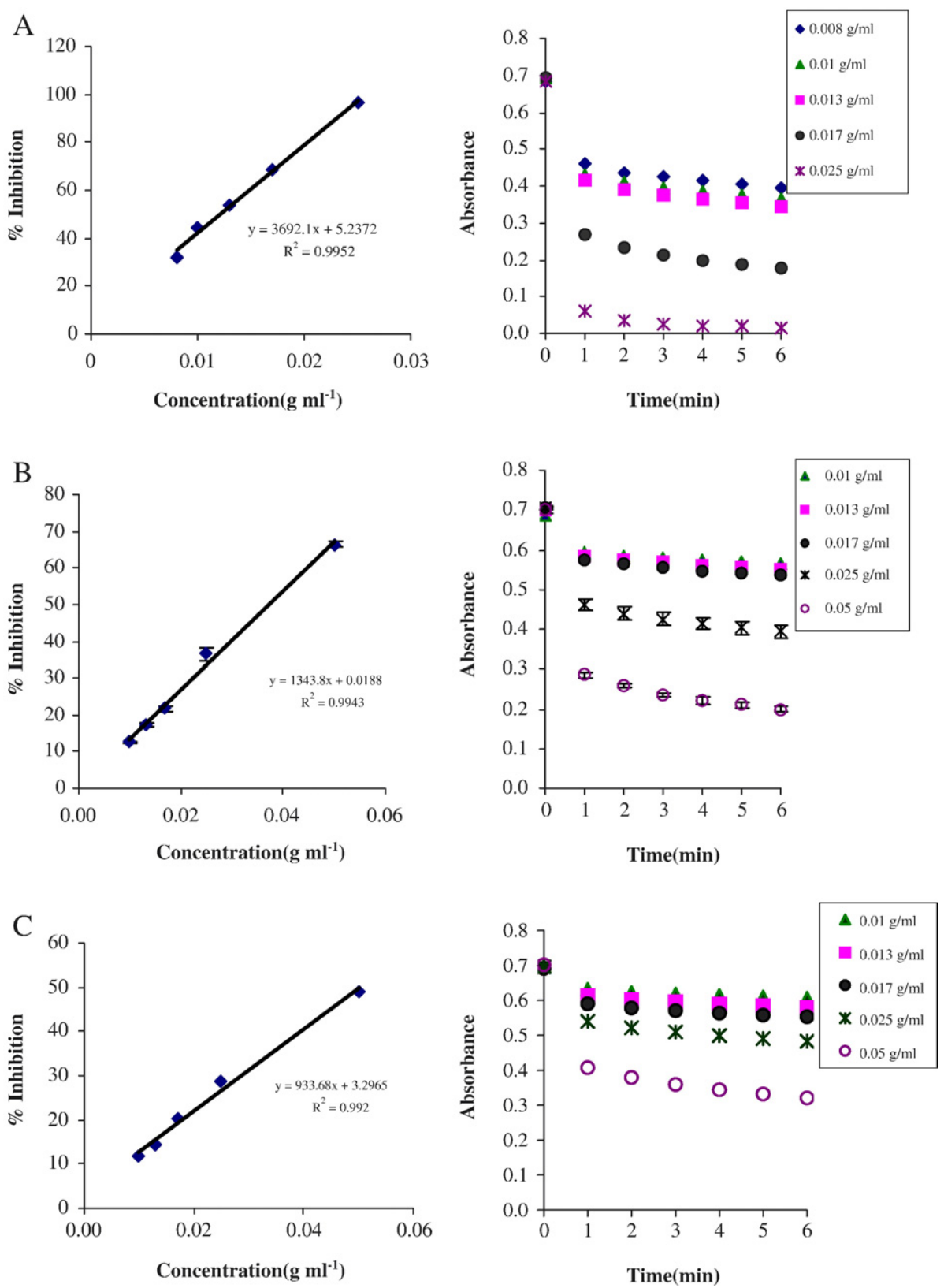

Fig. 5. Concentration-response curve for the absorbance at $734 \mathrm{~nm}$ for $\mathrm{ABTS}^{+}$as a function of concentration of ethanolic Ginkgo leaf extract solution and its time dependency (A) without zeolite, (B) after treatment with $5 \mathrm{~g}$ zeolite, (C) after treatment with $10 \mathrm{~g}$ zeolite.

additions, respectively. So, the extract solution after treatment with $5 \mathrm{~g}$ clinoptilolite-rich mineral yielded a steeper decrease in its absorbance value, indicating that it still possesses higher antioxidant activity.

The concentration of antioxidant giving the same percentage inhibition of absorbance of the radical cation, ABTS+ at $734 \mathrm{~nm}$ as $1 \mathrm{mM}\left(0.25 \mathrm{~g} \mathrm{l}^{-1}\right)$ Trolox is calculated in terms of TEAC. The antioxidant activities of standard antioxidants kaempferol, quercetin and propyl gallate (PG) were measured as 0.76 TEAC, 1.25 TEAC and 2.45 TEAC, respectively. These results were consistent with the TEAC values stated for kaempferol, quercetin and PG as 1.45 TEAC, 2.76 TEAC (Koleva et al., 2001) and 2.08 TEAC (Altiok, 2003), respectively. However, in complex mixtures, additive, synergistic, or inhibitory effects among the components have been observed. To evaluate the contribution of each single sample component, knowledge 
Table 3

TEAC values of the extract solutions, before and after adsorption with clinoptilolite-rich mineral

\begin{tabular}{llll}
\hline & $\begin{array}{l}\text { Before } \\
\text { adsorption }\end{array}$ & $\begin{array}{l}\text { Treated with } 5 \mathrm{~g} \\
\text { clinoptilolite-rich } \\
\text { mineral }\end{array}$ & $\begin{array}{l}\text { Treated with } 10 \mathrm{~g} \\
\text { clinoptilolite-rich } \\
\text { mineral }\end{array}$ \\
\hline $\begin{array}{c}\text { Ginkgo leaf } \\
\text { extract } \\
\text { solution }\end{array}$ & $\begin{array}{l}225.5 \\
\text { TEAC }^{\text {a, b }}\end{array}$ & 82.1 TEAC $^{\text {a, b }}$ & 57.03 TEAC $^{\text {a, b }}$ \\
\hline
\end{tabular}

a TEAC, Trolox equivalent antioxidant activity, expressed as mmol Trolox per $100 \mathrm{~g}$ dry weight.

b All values were mean of triplicates.

of its molecular structure is required. Unfortunately, in the search of novel active compounds in complex matrixes, this is not always possible ( Koleva et al., 2001). Therefore, the total antioxidant activity of plant extracts is rather expressed in terms of $\mu \mathrm{mol}$ of Trolox per $100 \mathrm{~g}$ of dry weight ( Cai et al., 2004). Therefore, in this study the antioxidant activities of the ethanolic Ginkgo biloba leaf extract solution was calculated as $225.5 \mathrm{mmol}$ Trolox per $100 \mathrm{~g}$ dry leaf powder.

When the antioxidant activity of the extract solutions were measured before and after adsorption with clinoptilolite-rich mineral, the total antioxidant activity of the extract solutions decreased due to adsorption of the phenolic constituents on the surface of clinoptilolite. The TEAC values of corresponding extract solutions and the change in their antioxidant activities due to adsorption were found as 82.1, and 57.03 after treatment with 5 and $10 \mathrm{~g}$ clinoptilolite-rich mineral, respectively (Table 3 ).

Besides, due to its ability to host pharmaceuticals, the adsorbed species on the clinoptilolite surface were assumed not to loose their antioxidant activity after adsorption. Dashevsky et al., (1995), investigated the process of adsorption-desorption of quercetin on the medicinal adsorbent "Dniper", a carbonic adsorbent with a high specific surface area and high adsorption capacity, in order to create drug forms with controlled release. They concluded their study as on the surface of the adsorbent, quercetin did not loose its antioxidant activity.

The antioxidant activity determinations using TEAC assay were performed for the unhydrolyzed and hydrolyzed extract solutions regarding the possibility of degradation of especially phenolic constituents under harsh hydrolysis conditions. Our results showed that around $30 \%$ of antioxidant capacity of the unhydyrolyzed extract solutions were lost after hydrolysis treatment. However, Cai et al. (2004) reported that flavonol aglycones, such as quercetin, myricetin, and kaempferol, containing multiple hydroxyl groups, had higher antioxi- dant activity than their glycosides, such as rutin, myricetin, astragalin. These results also suggest that there is a strong relationship between the total phenolic content and the antioxidant activity expressed as TEAC. Hence, the antioxidant activity in Ginkgo biloba leaf extract solutions is largely due to the presence of phenolic constituents.

\section{Conclusions}

The possible use of Turkish clinoptilolite-rich natural zeolite as a novel drug support for Ginkgo biloba L. extract was investigated throughout this study. Since the molecular size of the extracted species were much greater than the dimensional size of the clinoptilolite channels, only surface adsorption phenomena was expected to occur. Adsorption studies showed that flavonoid aglycone constituents were adsorbed on the surface of the zeolitic material. The decrease in the total antioxidant activity values due to adsorption demonstrated that the phenolic constituents i.e. flavonoid compounds were adsorbed on the surface of the zeolitic material. The use of clinoptilolite as a novel drug carrier for the flavonoid aglycone constituents should be developed regarding the release studies of those compounds as a future perspective of this study.

\section{Acknowledgement}

The authors are grateful for the research support provided by Turkish Government (project no. IYTE-98 K 122 130).

\section{References}

Altık, E., 2003. Production of proanthocyanidins from grape seeds. MSc. Thesis, Izmir Institute of Technology.

Aehle, E., Grandic, S.R., Ralainirina, R., Baltora-Rosset, S., Mesnard, F., Prouillet, C., Maziere, J., Fliniaux, M., 2004. Development and evaluation of an enriched natural antioxidant preparation obtained from aqueous spinach (Spinacia oleracea) extracts by an adsorption procedure. Food Chem. 86, 579-585.

Bayçin, D., Altiok, E., Ülkü, S., Bayraktar, O., 2007. Adsorption of olive leaf (Olea europaea 1.) antioxidants on silk fibroin. J. Agric. Food Chem. 55, 1227-1236.

Bonferoni, M.C., Cerri, G., de' Gennaro, M., Juliano, C., Caramella, C., 2007. $\mathrm{Zn}^{2+}$-exchanged clinoptilolite-rich rock as active carrier for antibiotics in anti-acne topical therapy: In-vitro characterization and preliminary formulation studies. Appl. Clay Sci. 36, 95-102.

Cai, Y., Luo, Q., Sun, M., Corke, H., 2004. Antioxidant activity and phenolic compounds of 112 traditional Chinese medicinal plants associated with anticancer. Life Sci. 74, 2157-2184.

Cerri, G., de' Gennaro, M., Bonferoni, M.C., Caramella, C., 2004. Zeolites in biomedical application: Zn-exchanged clinoptiloliterich rock as active carrier for antibiotics in anti-acne topical therapy. Appl. Clay Sci. 27, 141-150. 
Chiu, K.L., Cheng, Y.C., Chen, J.H., Chang, C.J., Yang, P.W., 2002. Supercritical fluids extraction of Ginkgo ginkgolides and flavonoids. J. Supercrit. Fluids 24, 77-87.

Dashevsky, A.N., Bucar, F., Kartnig, T., 1995. Investigations on the adsorption of quercetin on a medicinal carbonic adsorbentcontrolled release and stability. Pharmazie 50, 465-467.

Dubber, M.J., Sewram, V., Mshicileli, N., Shephard, G.S., Kanfer, I., 2005. The simultaneous determination of selected flavonol glycosides and aglycones in Ginkgo biloba oral dosage forms by highperformance liquid chromatography-electrospray ionisation-mass spectrometry. J. Pharm. Biomed. Anal. 37, 723-731.

Ellnain-Wojtaszek, M., Kruczynski, Z., Kasprzak, J., 2002. Variations in the free radical scavenging activity of Ginkgo biloba L. leaves in the period of complete development of green leaves to fall of yellow ones. Food Chem. 79, 79-84.

Ellnain-Wojtaszek, M., Kruczynski, Z., Kasprzak, J., 2003. Investigation of the free radical scavenging activity of Ginkgo biloba L. leaves. Fitoterapia 74, 1-6.

Farias, T., Ruiz-Salvador, A.R., Rivera, A., 2003. Interaction studies between drugs and a purified natural clinoptilolite. Microporous Mesoporous Mater. 61, 117-125.

Goh, L.M., Barlow, P.J., Yong, C.S., 2003. Examination of antioxidant activity of Ginkgo biloba leaf infusions. Food Chem. 82, 275-282.

Gray, D.E., Upton, R., Chandra, A., Porter, A., Harris, R.K., 2006. Quantitative analysis of flavonol glycosides in Ginkgo biloba: a comparison of two analytical methods. Phytochem. Anal. 17, 56-62.

Koleva, I.I., Niederlander, H.A.G., van Beek, T.A., 2001. Application of ABTS radical cation for selective on-line detection of radical scavengers in HPLC eluates. Anal. Chem. 73, 3373-3381.

Lai, S.M., Chen, R.L., Suen, S.Y., 2003. Adsorption separation for the extracts from Ginkgo biloba leaves. J. Liq. Chromatogr. 26, 2941-2960.

Lang, Q., Wai, C.M., 1999. An extraction method for determination of ginkgolides and bilobalide in ginkgo leaf extracts. Anal. Chem. 71, 2929-2933.

Li, W., Fitzloff, J.F., 2002. Simultaneous determination of terpene lactones and flavonoid aglycones in Ginkgo biloba by highperformance liquid chromatography with evaporative light scattering detection. J. Pharm. Biomed. Anal. 30, 67-75.

Lin-Chin, Lin, Y.R., Huang, C.Y., Wen, K.C., 2000. Evaluation of quantitative analysis of flavonoid aglycones in Ginkgo biloba extract and its products. J. Food Drug Anal. 8, 289-296.

Mantle, D., Eddeb, F., Pickering, A.T., 2000. Comparison of relative antioxidant activities of British medicinal plant species in vitro. J. Ethnopharmacol. 72, 47-51.

Ndjoko, K., Wolfender, J.L., Hostettmann, K., 2000. Determination of trace amounts of ginkgolic acids in Ginkgo biloba L. leaf extracts and phytopharmaceuticals by liquid chromatography-electrospray mass spectrometry. J. Chromatogr. B. 744, 249-255.

Pavelic, K., Hadzija, M., Bedrica, L., Pavelic, J., Dikic, I., Katic, M., Kralj, M., Bosnar, M.H., Kapitanovic, S., Polkak-Blazi, M., Krizanac, S., Stojkovic, R., Jurin, M., Subotic, B., Colic, M., 2001. Natural zeolite clinoptilolite: new adjuvant in anticancer therapy. Int. J. Mol Med. 78, 708-720.
Pietta, P., Simonetti, P., Gardana, C., Mauri, P., 2000. Trolox equivalent antioxidant capacity (TEAC) of Ginkgo biloba flavonol and Camellia sinensis catechin metabolites. J. Pharm. Biomed. Anal. 23, 223-226.

Poljak-Blazi, M., Katic, M., Kralj, M., Zarkovic, N., Marotti, T., Bosnjak, B., Sverko, V., Balog, T., Pavelic, K., 2001. Stud. Surf. Sci. Catal. 135, 5309-5316.

Ponto, L.L.B., Schultz, S.K., 2003. Ginkgo biloba extract: review of CNS effects. Ann. Clin. Biochem. 15, 109-119.

Re, R., Pellegrini, N., Proteggente, A., Pannala, A., Yang, M., RiceEvans, C., 1999. Antioxidant activity applying an improved ABTS radical cation decolorization assay. Free Radic. Biol. Med. 26, 1231-1237.

Rivera, A., Rodríguez-Fuentes, G., Altshuler, E., 2000. Time evolution of a natural clinoptilolite in aqueous medium: conductivity and $\mathrm{pH}$ experiments. Microporous Mesoporous Mater 40, 173-179.

Rivera, A., Farias, T., Ruiz-Salvador, A.R., de Menorval, L.C., 2003. Preliminary characterization of drug support systems based on natural clinoptilolite. Microporous Mesoporous Mater. 61, 249-259.

Rivera, A., Farias, T., 2005. Clinoptilolite-surfactant composites as drug support: a new potential application. Microporous Mesoporous Mater. 80, 337-346.

Sverko, V., Sobocanec, S., Balog, T., Colic, M., Marotti, T., 2004 Natural micronised clinoptilolite and clinoptilolite mixtures with urtica dioica extract as possible antioxidants. Food Technol. Biotechnol. 42, 189-192.

Top, A., Ülkü, S., 2004. Silver, zinc, and copper exchange in a Naclinoptilolite and resulting effect on antibacterial activity. Appl. Clay Sci. 27, 13-19.

van Beek, T.A., 2002. Chemical analysis of Ginkgo biloba leaves and extracts. J. Chromatogr. A 967, 21-55.

Wang, F.M., Yao, T.W., Zeng, S., 2003. Determination of quercetin and kaempferol in human urine after orally administrated tablet of Ginkgo biloba extract by HPLC. J. Pharm. Biomed. Anal. 33, 317-321.

Wood, J.E., Senthilmohan, S.T., Peksin, A.V., 2002. Antioxidant activity of procyanidin-containing plant extracts at different $\mathrm{pHs}$. Food Chem. 77, 155-161.

Xu, M., Shi, Z., Shi, R., Liu, J., Lu, Y., He, B., 2000. Synthesis of the adsorbent based on macroporouscopolymer MA-DVB beads and its application in purification for the extracts from Ginkgo biloba leaves. React. Funct. Polym. 43, 297-304.

Xu, Z., Li, L., Wu, F., Tan, S., Zhang, Z., 2005. The application of the modified PVDF ultrafiltration membranes in further purification of Ginkgo biloba extraction. J. Membr. Sci. 255, 125-131.

Yoon, S.Y., Choi, W.J., Park, J.M., Yang, J., 1997. Selective adsorption of flavonoid compounds from the leaf extract of Ginkgo biloba L. Biotechnol. Tech. 11, 553-556.

Yu, F.C., Lai, S.M., Suen, S.Y., 2003. Extraction of flavonol glycosides from Ginkgo biloba leaves and their adsorption separations using hydrophobic and anion-exchange membranes. Sep. Sci. Technol. $38,1033-1050$. 